\title{
Does Privatising Public Service Provision Reduce Accountability?
}

\author{
Matthew Ellman* \\ Universitat Pompeu Fabra
}

October 2006

\begin{abstract}
This paper studies how privatising service provision (shifting control rights and contractual obligations to providers) affects accountability. There are two main effects. (1) Privatisation demotivates governments from investigating and responding to public demands, since providers then hold up service adaptations. (2) Privatisation demotivates the public from mobilising to pressure for service adaptations, since providers then indirectly holdup the public by inflating the government's cost of implementing these adaptations. So, when choosing governance mode, politicians may be biased towards privatising as a way to escape public attention; relatedly, privatising utilities may reduce public pressure and increase consumer prices.
\end{abstract}

Jel Classification numbers: D23.

Keywords: Public Services; Privatisation; Voter Mobilisation; Accountability; Government Responsiveness; Contract Length; Incomplete Contracts; Holdup.

${ }^{*}$ I am grateful to Oliver Hart, Paul Grout, Carol Propper and participants at the Toulouse Conference on Public Services and Management (IDEI-VEOLIA, 2006), the Public Economics UK (PEUK) Conference at Bristol (2006), the Regulation Jornades (Barcelona, 2006) the ESF-CEPR Conference on Governance (Bristol, 2006), the 3rd Seminar on Government Restructuring (Real Complutense at Harvard), the Public Economic Theory conference (Hanoi, PET 2006) and the Jornadas de Economía Industrial (IESE, Barcelona, 2006) for many helpful comments. This study received financial support from the European Commission through the Integrated Project "Reflexive Governance" Integrated Project (CIT3-513420), the Spanish Ministry of Science and Technology (BEC 2003-00412) and CREA (Barcelona Economics). Comments gratefully received at Matthew.Ellman@upf.edu. 
"[T]he key to reforming the public sector is not the profit motive, but democracy and accountability." 1

\section{Introduction}

Central and local governments are contracting out the provision of an increasingly broad range of public services. In this paper, I investigate the theoretical basis of concerns that privatising provision is reducing political accountability. Political accountability does remain crucial public funding weakens the provider's direct (market price) accountability to consumers - but the voting public's control over providers was already indirect under public governance, since politicians generally delegate provision tasks to unelected agents. So privatising provision is only a problem if it restricts politicians' ability to transfer public pressure onto the service providing agents, or demotivates the public from holding politicians accountable.

The recent furore over free school dinners in the U.K. offers a good illustration. In the aftermath of celebrity chef Jamie Oliver's televised criticisms of school dinner quality in early 2005, the British government rushed to quench mounting public discontent by committing to higher standards. However, state schools that outsource catering were unable to force their providers to meet these standards; Lawrence and Quarmby (2005) reported how schools "locked into 25-year contracts through private finance initiatives are finding that they cannot rid their menus of junk food despite the government's pledge". ${ }^{2}$ By contrast, state schools with publicly-managed catering were able to adapt quickly to the public demand for healthier school dinners.

To analyse the adaptation inflexibilities suggested by this example, I present a model of service provision that adds two novel features to the set-up of Hart, Shleifer and Vishny (1997), henceforth denoted HSV. In HSV (and other formal work), the public are passive bystanders and the government is not involved in adaptation. Hart (2003) writes: "the idea that government ownership leads to more entrepreneurship by bureaucrats seems less [plausible]." However, to be accountable, politicians must investigate and discover how to satisfy public demands. Furthermore, to hold politicians accountable, the public must discover their own preferences, communicate them to the politicians, and mobilise to pressure for service improvements. So

\footnotetext{
${ }^{1}$ David Hinchliffe, Chair, House of Commons Health Select Committee, in Pollock, Shaoul and Player (2001).

${ }^{2}$ Catering contracts are typically shorter (at 5 years), but still problematic, especially since it is hard for activists to stay mobilised and maintain issue salience. E.g., in Islington, London, where the private company, Cambridge Education Authority (CEA), runs the state schools, CEA signed 5-year contracts outsourcing provision of school dinners to a private caterer (Scolarest) and CEA's schools have (so far) neither managed to negotiate an opt out from Scolarest, nor an improvement in Scolarest's service quality.
} 
in my model: (1) the government (e.g. city mayor) exerts effort to understand and calculate how to respond to public demands; (2) the public (who are only third parties to the service contract) exert efforts to evaluate service quality, discover feasible alternatives and pressure for change.

First, I show that when the government cannot anticipate desirable service adaptations in its outsourcing contracts, it ends up having to pay more for these adaptations under private than public provision. My main result here is that this cost inflation demotivates both the government and the public from exerting the efforts that generate accountability. Second, I compare the political and social benefits from privatising; politicians may bias towards privatising so as to reduce public efforts to hold them accountable. Unlike existing theories (e.g. HSV) on how privatisation might lower service quality, the mechanism that drives my results can also explain why privatising tends to raise consumer service prices (see Kwoka (2002 and 2005) and Guasch (2005) for empirical evidence ${ }^{3}$ ). The reason is that privatising dissuades the public from mobilising, so politicians have less incentive to pay the costs of restraining consumer prices.

I illustrate the underlying logic in the context of school dinner catering in a village school. The village mayor is too busy to manage catering directly so she pays a manager to provide the school dinners. In the case of public provision, the mayor retains control of the assets needed for catering and pays the manager to devote time to run the service according to her orders. By contrast, when the mayor opts for private provision, she gives the manager significant control rights and signs a long-term contract guaranteeing the manager a fixed payment in return for a well-defined catering service. As in HSV, privatising provision stops the mayor from holding up the manager, so the manager's cost-cutting incentives rise. ${ }^{4}$ Unlike in HSV, the underlying problem with privatisation is that the mayor may then rely on the manager's cooperation in order to exploit adaptation gains.

For instance, if activists convince the mayor that the dinners must become healthier, the mayor cannot oblige the private manager to adapt the menus accordingly; furthermore, (usu-

\footnotetext{
${ }^{3} \mathrm{~A}$ number of empirical papers show that privatisation can raise prices. For instance, privatisation of electricity utilities was widely predicted to lower consumer prices, but Kwoka (2002 and 2005) compares public and private provision of electricity in the U.S. and finds that "public ownership is associated with significantly lower [residential consumer] prices" as well as higher quality. Similarly, Guasch (2005) shows that privatisation in many countries has led to higher prices for a range of service sectors.

${ }^{4}$ While the mayor can hold up a public manager by paying less after the manager cuts his cost, a private contract fixes what the mayor must pay for the basic catering service. So privatisation can reduce basic service costs. Formally, the (long-term) private contract prevents holdup of the manager's specific investment (and enhanced control rights enable the private manager to exploit his cost innovations).
} 
ally) the mayor cannot credibly pay an alternative manager to provide healthier food alongside the basic service from the incumbent manager; such a side-trade would either partially duplicate the incumbent's basic service or waste economies of scope)..$^{5}$ By contrast, under public provision, the mayor can usually replace, over-rule or sideline the incumbent catering manager for disobeying orders to adapt to healthier ingredients. So a private (but not a public) manager can hold up the mayor for a share of the mayor's gain from adaptation. This holdup demotivates the mayor from attentively listening to public demands and working out how to satisfy them.

The private manager can also indirectly hold up the activists. Activist pressure raises the mayor's adaptation benefit. The private manager therefore charges the mayor an inflated price for adaptation. Since the mayor pays using public money, this price inflation demotivates the public from participating in service evaluation and pressuring for service improvements.

These direct and indirect holdup effects are usually mutually reinforcing: the mayor has no incentive to investigate public concerns if the public do not mobilise enough to hold the mayor accountable; conversely, the public only benefit from mobilising if the mayor is receptive to pressure. This strategic complementarity raises the benefit from keeping catering in-house to raise dynamic accountability relative to the benefit from outsourcing to raise the provider's cost-cutting incentives.

The tradeoff also depends on the difficulty of accessing alternative providers alongside a long-term contract. So I apply Ellman (2006) to suggest how contract design can limit the accountability problem and to predict where privatisation will be particularly harmful. I also briefly discuss the possibilities of mixing public and private delivery options (see Warner and Hefetz (2006)) and of contracting out to not-for-profit organisations (see Besley and Ghatak (1998), Bennet and Iossa (2005)) or neighbouring municipalities (see Bajari and Tadelis (2006)).

My positive analysis of the privatisation decision in section 5, simply compares the politician's choice of provision mode with that which voters would select in a referendum (or in an election where politicians compete on public and private provision platforms). I characterise (the "avoid the public eye") setting where politicians are biased (relative to voter preferences) towards privatising.

The paper is organised as follows. Section 2 presents the basic model of service provision. Section 3 solves the model for subgame-perfect equilibria when the provision mode is predetermined. Section 4 solves for the provision modes that would be chosen by first the

\footnotetext{
${ }^{5}$ The basic service contract may even contain an exclusive territory clause that directly prevents the mayor from side-trading with alternative caterers. Also to exploit the adaptation opportunity, the mayor could need control rights that she only retains in the public case, so the general ideas summarised in Hart (1995) apply.
} 
government and then the people. Section 5 presents the public pressure version of the model. Section 6 discusses the results, presents alternative perspectives and applies the analysis to help understand specific case studies of privatised services. Section 7 concludes.

\subsection{Related Literature}

There are many interesting papers on public-private governance following the framework of HSV or analyse contracting under asymmetric information. ${ }^{6}$ To the best of my knowledge, none of them give an active role to either the public or the government. These two extensions on HSV are crucial in my analysis of accountability. (I also extend existing work in the HSV vein by building on Ellman's (2006) model of how and when long-term contracts interfere with market forces.) Existing results are based on distorted incentives for the manager/contractor. My results are based on loss of incentives for the government and public. My accountability explanation shares the existing prediction of low quality, but the mechanism is very different, as indicated by the unique, direct explanation of Kwoka's (2002 and 2005) and Guasch's (2005) evidence on pricing.

My work is also linked to the literature on political economy and influence. Milgrom and Roberts (1988) show how restrictive commitments may serve to reduce undesirable influence within firms. Bennedsen (2000) develops a common agency model where politicians adjust/distort their policies to earn contributions from lobbyists. The public are passive (implicitly susceptible in elections to the persuasion of well-funded polititical parties), but the behaviour of the union lobby bears some parallels with the activist public in my model; Bennedsen shows that privatising control can demotivate lobbying by unions. ${ }^{7}$ For my second (pressure) interpretation of the public's role in service adaptation, I appeal to Besley and Burgess's (2001 and 2002) model of accountability. Their model derives how governments become more responsive to people when people become more aware of how government actions affect them. In

\footnotetext{
${ }^{6}$ One important alternative perspective maintains that privatisation reduces government access to information (see e.g. Shapiro and Willig (1990) and Schmidt (1996)). My results could be derived from this perspective, since privatisation would then hinder the government in negotiating acceptable terms of trade for valuable adaptations - asymmetric information generates an "undertrading problem". Another important perspective is that of Laffont and Tirole (1991) who show that privatisation introduces a common agency problem by adding a new set of principals - the shareholders. My analysis emphasises a different additional set of principals - the voters - whose control is limited to voting in elections.

${ }^{7} \mathrm{My}$ approach demonstrates how increased governmental control rights invite greater pressure by the general public and not just organised lobbyists. Furthermore, I have unique equilibria and do not need Bennedsen's (2000) assumption that shareholders and unionists can contract with the government while unable to negotiate with each other. On the other hand, Bennedsen (2000) covers the role of shareholders: privatising cash-flow rights (corporatisation) creates a shareholder lobby that counterbalances the union lobby.
} 
their work, the freedom of the press determines public awareness. In my analysis, it is activist members of the public who determine public awareness (perhaps by encouraging, persuading and helping newspapers to report on the public service issue).

\section{The Model}

This section presents a simple model of the choice between public and private modes of governance for a public service (such as park maintenance, road maintenance, garbage collection, care of the elderly, health care, transportation, water, education or school dinner catering). I endogenise the accountability of politicians to changing public demands by adding a third party (the public) within the framework of HSV. So there are three actors: a government G (e.g. a mayor, local government or elected agency head), a manager $\mathrm{M}$ and an action group A, representing aggregate public activism and participation in politics.

$\mathrm{G}$ uses public funds to organise service provision on the public's behalf. $\mathrm{G}$ always delegates the service provision task to a manager (M), but can choose between public ("in-house") provision and private provision ("outsourcing" to a private organisation). So M can be a public manager/employee or a private manager. (As in HSV, funding is fully public and I model manager-owned firms.)

There are two crucial differences between public and private provision: privatisation formally delegates residual control and uses long-term performance contracts to delegate specific service obligations. Under private provision, $\mathrm{G}$ and $\mathrm{M}$ sign a long-term contract committing $\mathrm{G}$ to pay for, and $\mathrm{M}$ to provide, a defined public service over a defined period (see $\alpha$ below); $\mathrm{G}$ also transfers to $\mathrm{M}$ sufficient residual rights of control to provide this service free of interference (temporarily in a concession or forever as when $\mathrm{M}$ owns key assets). Under public provision, G retains ownership and control; typically $\mathrm{G}$ then covers input costs and compensates M's exclusive labour dedication; see Ellman (1999) and Levin and Tadelis (2006). The public/private distinction matters, because it affects what happens when $\mathrm{G}$ and $\mathrm{M}$ need to make unanticipated changes in their joint trade; over time, $\mathrm{G}$ and $\mathrm{M}$ may learn better ways to write contracts or satisfy a given contract.

At the start of their relationship, G and $\mathrm{M}$ can only negotiate a "basic" performance contract, $X$. I normalise the non-contingent transfer in $X$ to that which just compensates for standard costs of provision: $X$ generates (net) payoff flows of $b$ for $\mathrm{G}$ and $w(e)$ for $\mathrm{M}$ where $w(e)$ is M's cost advantage (over a standard provider) from investing $e$ in specialising to $\mathrm{G}$. While $\mathrm{M}$ invests $e$ to cut costs, $\mathrm{G}$ and $\mathrm{A}$ invest efforts $i$ and $j$ (respectively) to discover improved policies and technologies. These efforts, motivated below, permit $\mathrm{G}$ and $\mathrm{M}$ to adapt 
the basic contract $X$ to changing public preferences and possibilities. (I neglect M's potential role in discovering adaptations, because M's adaptation incentives would not directly vary with the governance structures I analyse.)

As elected delegate of the public, it is G's job to pressure $M$ to satisfy changes in effective public demand: $G$ can exert effort $i$ to discover what the public want and how to satisfy their demands. The public can also participate: A exerts effort $j$ in investigations to discover socially valuable adaptations and in political participation (or communication) to ensure that $\mathrm{G}$ understands public demands. Efforts $i$ and $j$ combine to increase the expected increase in social value from implementing the best service adaptation that becomes feasible. (Note that best is defined from $\mathrm{G}$ and M's bilateral perspective since $\mathrm{A}$ is not directly involved in negotiation.) I denote the corresponding adapted contract by $Z$, again with the non-contingent transfer set to just compensate the standard costs of provision. For simplicity, I assume that, while $e$ is specific to $\mathrm{G}, e$ helps M satisfy $Z$; so M's payoff from enforcement of contract $Z$ throughout the trading period is again $w(e)$. G's payoff from $Z$ is $b+v(i, j)$ where $v \geq 0$, increasing and concave in $i$ and $j$, represents the gain in public welfare from the adaptation, as internalised by $\mathrm{G}$.

Until section 5 (on public pressure), I assume G internalises a fraction $g$ of public welfare, where $g \leq 1$ represents G's benevolence (public-service orientation) and/or G's electoral motivation to gain public approval. Similarly, A internalises a fixed fraction $a \leq 1$ of public welfare; typically $a<1$, because the public face a free-rider problem in helping $\mathrm{G}$ to improve public services. ${ }^{8}$ So payoffs from $X$ are $b$ for $\mathrm{G}, \frac{1}{g} b$ for the public, $\frac{a}{g} b$ for A, $w(e)$ for M; payoffs from $Z$ are $v(i, j)$ for $\mathrm{G}, \frac{1}{g} v(i, j)$ for the public, $\frac{a}{g} v(i, j)$ for $\mathrm{A}$ and $w(e)$ for $\mathrm{M}$.

It is also important for $\mathrm{G}$ to be accountable to public demands for reducing taxation. I assume a shadow value $1+\lambda$ of public funds where $\lambda>0$ represents tax distortions; to simplify notation, I use the parameter $l=\frac{1+\lambda}{g}$ which captures G's marginal payoff cost of using public funds. I normalise time discounting to zero. If $\mathrm{G}$ pays $\mathrm{M}$ up-front transfers $t_{0}$ and subsequent transfers $t$ in addition to the transfers enforced by contract $Z$, then G, A and M's overall payoffs are:

$$
\begin{aligned}
u_{G} & =b+v(i, j)-l\left(t_{0}+t\right)-i \\
u_{A} & =\frac{a}{g}\left(b+v(i, j)-l\left(t_{0}+t\right)\right)-j \\
u_{M} & =t_{0}+t+w(e)-e
\end{aligned}
$$

\footnotetext{
${ }^{8}$ E.g. $a=\frac{1}{N}$ if effective mobilisation $j$ equals the sum $\Sigma_{n=1}^{N} j_{n}$ of $N$ individual efforts $j_{n}$ chosen simultaneously by a homogeneous and uncoordinated public.
} 
The following regularity assumptions guarantee sufficiency of first-order conditions.

Assumption $1 w^{\prime \prime}(e)<0<w^{\prime}(e) \forall e \geq 0$ and $\lim _{e \rightarrow 0_{+}} w^{\prime}(e)=\infty, \lim _{e \rightarrow \infty} w^{\prime}(e)=0$.

Assumption $2 v(i, j)$ is negative semi-definite and $\lim _{i \rightarrow 0_{+}} v_{i}(i, j)=\lim _{j \rightarrow 0_{+}} v_{j}(i, j)=\infty$, $\lim _{i \rightarrow \infty} v_{i}(i, j)=\lim _{j \rightarrow \infty} v_{j}(i, j)=0, \forall i, j \geq 0$.

I assume information is symmetric and $\mathrm{M}$ and $\mathrm{G}$ negotiate a symmetric Nash bargain. So $Z$ is enforced in equilibrium. Privatisation and contract length matter because they affect default outcomes in bargaining and hence the equilibrium choices of $i, j, e$. I capture these effects in a simple four-stage model and then relate to the arbitrary finite horizon setting of Ellman (2006). I write 'fixing $\alpha$ ' to denote commitment to enforcement of contract $X$ for a fraction $\alpha$ of stage 3 trading; no contract is enforced on the remainder and I denote this by the "null" contract $\Phi .{ }^{9}$ Timing:

Stage 0: G, M negotiate over stage 3 contracts $\{\Phi, X\}$, fixing $\alpha$ and transfer $t_{0}$.

Stage 1: G, A, M sink their investments $i, j, e$.

Stage 2: G, M negotiate over stage 3 contracts $\{\Phi, X, Z\}$ and additional transfer $t$.

Stage 3: G, M trade (jointly or with their market alternatives).

The transfer $t_{0}$ agreed up-front (i.e. at stage 0) cannot depend on observed investments, so it plays no role in determining investment efficiency. The subsequent transfer $t$, negotiated on top of contract $Z$ at stage 2 , depends on the stage 2 default payoffs which in turn depend on the mode of governance and length of contract as I now show.

\subsection{Effort under public provision}

Under public provision, $\mathrm{M}$ has to be continually motivated to implement the basic trade. I assume $\mathrm{G}$ needs a basic service enough $(b>0)$, that in default of renegotiation to motivate $\mathrm{M}, \mathrm{G}$ would find an alternative manager $\mathrm{M}^{\prime}$ to implement the adapted service. Investments $i$ and $j$ are not specific to $\mathrm{M}$, so $\mathrm{G}$ can exploit $i$ and $j$ in this default. G's default payoff (see interpretation just below) is

$$
b-l t_{0}+v(i, j)
$$

Normalising M's alternative payoff to 0 , M's default payoff is simply $t_{0}$.

G's maximal gain from renegotiation is therefore $l \cdot w(e)$. In the Nash bargain, G gains $\frac{l \cdot w(e)}{2}$ and $\mathrm{M}$ gains $\frac{w(e)}{2}$. So in subgame perfect equilibrium, G chooses $i$ to maximise

$$
b+v(i, j)-l t_{0}+\frac{l \cdot w(e)}{2}-i
$$

\footnotetext{
${ }^{9} \mathrm{P}$ and $\mathrm{A}$ may trade in stage 1 , but I leave implicit the contract that enforces this trade.
} 
and $\mathrm{M}$ chooses $e$ to maximise

$$
t_{0}+\frac{w(e)}{2}-e
$$

Adaptations have an externality on A. A optimally influences the outcome by setting $j$ to maximise

$$
\frac{a}{g}\left(b+v(i, j)-l t_{0}+\frac{l \cdot w(e)}{2}\right)-j
$$

The investment efforts sunk in stage 1 are therefore characterised by the first-order conditions

$$
v_{i}(i, j)=1 \quad w^{\prime}(e)=2 \quad \frac{a}{g} v_{j}(i, j)=1
$$

\subsection{Effort under private provision}

Under private provision, $\mathrm{G}$ has less power and credibility to exploit investments $i$ and $j$ (see next subsection); so in default of renegotiation, $\mathrm{G}$ only appropriates a fraction $1-k$ of the adaptation return $v(i, j)$, unless the contract has expired, in which case $\mathrm{G}$ appropriates the full marginal return $v(i, j)$ by negotiating with $\mathrm{M}^{\prime}$. If the contract has length $\alpha$, G's default payoff is

$$
b-l t_{0}+(\alpha(1-k)+(1-\alpha)) v(i, j)=b-l t_{0}+(1-\alpha k) v(i, j)
$$

Meanwhile, the contract, protects M's cost-reduction efforts, by forcing $\mathrm{G}$ to pay a fixed price for the basic service. So M appropriates the full cost reduction $w(e)$ over fraction $\alpha$ of stage 3. M's default payoff under privatisation is

$$
t_{0}+\alpha \cdot w(e)
$$

G's maximal gain from renegotiation is therefore $l(1-\alpha) w(e)+\alpha k \cdot v(i, j)$. G and M's respective renegotiation gains are $\frac{1}{2}$ and $\frac{1}{2 l}$ of this sum. So $\mathrm{G}$ chooses $i$ to maximise

$$
b-l t_{0}+\left(1-\frac{\alpha k}{2}\right) v(i, j)+\frac{l(1-\alpha)}{2} w(e)-i
$$

and $\mathrm{M}$ chooses $e$ to maximise

$$
t_{0}+\frac{1+\alpha}{2} w(e)+\frac{\alpha k v(i, j)}{2 l}-e
$$

while A responds to the externalities by choosing $j$ to maximise

$$
\frac{a}{g}\left(b-l t_{0}+\left(1-\frac{\alpha k}{2}\right) v(i, j)+\frac{l(1-\alpha)}{2} w(e)\right)-j
$$

The first-order conditions are now

$$
v_{i}(i, j)=\frac{2}{2-\alpha k} \quad w^{\prime}(e)=\frac{2}{1+\alpha} \quad \frac{a}{g} v_{j}(i, j)=\frac{2}{2-\alpha k}
$$




\section{$2.3 \quad$ Interpretations of $k$ and $\alpha$}

There are two types of tradeoff associated with privatisation. One from the shift in control rights, the other from performance contracting (which shifts M's default obligations). Both changes generate a similar tradeoff between incentives for cost-cutting by $\mathrm{M}$ and incentives for accountability efforts by $\mathrm{G}$ and $\mathrm{A}$. I focus on the contractual dimension and then briefly describe the control rights interpretation.

If $\mathrm{G}$ and $\mathrm{M}$ do not sign a long-term performance contract (that is, an agreement at stage 0 to enforce $X$ at stage 3 ), then in default of an agreement at stage 2, G switches to trading with a substitute $\mathrm{M}^{\prime}$ of $\mathrm{M}$ who provides the adapted service at the standard cost (M's cost plus $w(e))$. This is credible, since $b>0$ induces $\mathrm{G}$ to replace or sideline an uncooperative public manager. Hence G's payoff of $b+v(i, j)-l \cdot t_{0}$. On the other hand, if $\mathrm{G}$ and $\mathrm{M}$ commit to $X$ at stage 0 , they cannot switch to alternative trades. They might still engage in "side-trades." M's side-trading returns are independent of $e, i, j$, so I normalise M's additional side-trade value to 0 - hence M's default payoff of $t_{0}+w(e)$. Meanwhile, G could pay a substitute provider $\mathrm{M}^{\prime}$ to provide the service adaptation alongside the basic public service provided by M. Unfortunately, this market access by G is rarely so effective: (1) the longterm contract may directly restrict this market access (e.g. private caterers usually demand exclusive territories) or transfer to $\mathrm{M}$ control rights that $\mathrm{G}$ needs for adaptations (e.g. access to the school kitchen); (2) G cannot credibly duplicate the basic service by buying the adapted service from $\mathrm{M}^{\prime}$ unless the additional value from adaptation is very high; (3) even when it is technologically feasible to have $\mathrm{M}^{\prime}$ provide the adaptation service without the basic service, this would waste the economies of scope from having a single party provide and coordinate them. To capture G's reduced market access, I assume side-trading increases G's payoff $b-l t_{0}$ (from the basic contract at transfer price $\left.t_{0}\right)$ by $(1-k) v(i, j)$, where $k \in(0,1]$ captures the "market-shielding" effect of contracting (see Ellman (2006) for a model endogenising $k$ ).

The performance contracting set-up abstracts from the restrictions typically imposed on employees, so public provision is equivalent to setting $\alpha=0 .{ }^{10}$ To link to HSV's theory of privatisation based on shifts in control rights, I fix contract length (as in HSV), and reinterpret $\alpha$ as the proportion of control rights held by M relative to G. So raising $\alpha$ enhances M's ability to exploit $e$ without needing G's cooperation, but (as in Grossman and Hart (1986) raising $\alpha$ also lowers G's control rights and hence G's ability to exploit $i$ and $j$. Parameter $k$ now captures asset-specificity. This aspect of privatisation lowers adaptation incentives, because M can then hold up any asset-specific components of $i$ and $j$ even after the performance contract

\footnotetext{
${ }^{10} \mathrm{I}$ also abstract from the transaction costs of designing $X$ in advance (i.e. at stage 0 ) which, being avoidable by the $\alpha=0$ 'corner solution', would favour public provision (see Bajari and Tadelis (2003)).
} 
expires.

\section{Accountability comparisons}

The above pair of first-order conditions demonstrate how privatisation increases M's costcutting incentives from $\frac{1}{2} w^{\prime}(e)$ in equation 4 to the higher fraction $\frac{1+\alpha}{2}$ of $w^{\prime}(e)$ in equation 8 , but decreases G's incentives to support adaptations down from the full marginal incentive $v_{i}(i, j)$ to the fraction $\frac{2-\alpha k}{2}$ of $v_{i}(i, j)$. Privatisation also decreases A's incentives to work for adaptations (see 3.2 below on this indirect holdup) from the full margin $\frac{g}{a} v_{j}(i, j)$ down to the fraction $\frac{2-\alpha k}{2}$ of $\frac{g}{a} v_{j}(i, j)$. Furthermore, when $i$ and $j$ are strategic complements, privatisation's negative effects on $i$ and $j$ are mutually reinforcing as I show in 3.3. To clarify the accountability interpretations of these effects, I describe in turn the cases where A takes no action, where $\mathrm{G}$ takes no action and then the common case where A and G's efforts are strategic complements.

\subsection{Government attentiveness}

To isolate the effect of privatisation on G's incentives, I first analyse the case where $v=v(i)$, independent of $j . v(i)$ measures G's success in identifying or discovering adaptations that are valued by the public (and politically salient). So $i$ represents G's efforts to pay attention to public concerns about service quality. For instance, when there is a public demand for a concrete change, $i$ raises the probability that $\mathrm{G}$ recognises that the demand is serious (enough to affect G's reelection) and/or $i$ raises the probability that G works out how to satisfy public demands. So $v(i)$ can be interpreted as a measure of G's responsiveness to public demand how likely it is that $\mathrm{G}$ manages to please or placate the general public. Attentiveness $i$ raises G's ability and propensity to respond.

Under public provision, G's effort $i$ is determined by the first order condition, $v^{\prime}(i)=1$ (see equation 4). $\mathrm{M}$ is unable to hold up $\mathrm{G}$, because investment $i$ is general and $\mathrm{G}$ can therefore exploit $i$ by replacing or sidelining an uncooperative $\mathrm{M}$. In contrast, under private provision, M can hold up G, because $i$ is an adaptation investment; the greater the basic contract's duration $\alpha$, the longer $\mathrm{G}$ must wait before able to access effective market alternatives. G's incentive is thereby reduced by the fraction $1-\frac{\alpha k}{2}$ (see equation 8). Accordingly, $i^{\text {public }}>i^{\text {private }, \alpha}$ for any contract of length $\alpha>0$ and privatisation reduces G's attentiveness by more, the greater is $\alpha$ (since $1-\frac{\alpha k}{2}$ falls with $\alpha$ ). Since the social return on $i$ is given by $\frac{1}{g} v(i)$ and $g<1$, public provision also generates under-attentiveness. So private provision, by exacerbating this problem, is clearly harmful to accountability. The following proposition records these 
points along with the, now well-known, advantage of privatisation - namely, that long-term contracting increases M's incentive $\left(\frac{1+\alpha}{2} w^{\prime}(e)\right)$ to cut provision costs.

Proposition 1 Governments are more attentive and responsive to public demand when service provision is public. On the other hand, privatisation motivates cost-reducing investments by the service-provider. Increasing the private provider's contract length $\alpha$ augments both the accountability deficit and cost advantage of the private mode. For $v=v(i): e^{\text {public }}<$ $e^{\text {private }}(\alpha), i^{\text {public }}>i^{\text {private }}(\alpha), \forall \alpha>0$ and $\frac{d e^{\text {private }}(\alpha)}{d \alpha}>0, \frac{d i^{\text {private }}(\alpha)}{d \alpha}<0$.

In sum, privatisation requires long-term contracts and transfer of control rights to protect M's investments $e$ in cost-reduction from G's market threats, but the long-term contracts and reduced control rights reduce G's access to market alternatives that protect G's adaptation investments. So while privatisation reduces G's holdup of M's self-investments (in costreduction), it increases M's holdup of G's adaptation investments. Privatisation encourages cost reduction but demotivates $\mathrm{G}$ from working to understand and satisfy changing public demand. This result is directly relevant for situations where public pressure is independent of government attentiveness and service privatisation. For instance, A might be an action group whose members' time and budget constraints are always binding or the public might be entirely passive (beyond voting in elections). In the next section, I allow for an active role of the public in generating political accountability.

\subsection{Public mobilisation}

In this subsection, I show how privatisation enables $M$ to effect what I call an "indirect" hold up on A. The private provider $\mathrm{M}$ cannot hold up the public directly, since the public never negotiate or pay $\mathrm{M}$ directly. However, when the public invest $j$ in mobilisation, they create an adaptation surplus. I show that, provided $\mathrm{M}$ is private, $\mathrm{M}$ is able to expropriate a share of this surplus by inflating the price of adaptation charged to G. In this way, M effectively siphons money from the public, since $\mathrm{G}$ pays off $\mathrm{M}$ using public funds.

Formally, I study an activist subgroup of the public, A. A invests effort $j$ to pressure $\mathrm{G}$ to make an adaptation. This raises G's value from adapting. Under private provision, G relies on $\mathrm{M}$ to implement the adaptation, so M can demand a share of G's benefit. Because $\mathrm{G}$ transfers utility to $\mathrm{M}$ using public funds, A suffers when M holds up G. Since A is the investor, the real holdup is perpetrated by $\mathrm{M}$ against $\mathrm{A}$, but it is indirect since $\mathrm{M}$ cannot negotiate with $\mathrm{A}$. Under public provision, $\mathrm{G}$ can get $\mathrm{M}$ to implement the adaptation at actual cost, so $\mathrm{A}$ evades the indirect holdup. The impact of the indirect holdup introduced by privatisation is that $\mathrm{A}$ has less incentive to mobilise. This can be seen by comparing A's first-order conditions in 
equations 4 and 8; private provision reduces A's adaptation incentives by the fraction $\frac{2}{2-\alpha k}$. Again public provision has an accountability advantage over private provision. The following proposition records this result, which simply reiterates the tradeoff of public accountability against privatisation's cost-efficiency.

Proposition 2 The public are more likely to mobilise and induce valuable service adaptations when service provision is public, but as before, privatisation better motivates costreducing investments by the service-provider. This tradeoff is again increasing in the private provider's contract length $\alpha$. For $v=v(j): e^{\text {public }}<e^{\text {private }}(\alpha), j^{\text {public }}>$ $j^{\text {private }}(\alpha), \forall \alpha>0$ and $\frac{d e^{\text {private }}(\alpha)}{d \alpha}>0, \frac{d j^{\text {private }}(\alpha)}{d \alpha}<0$.

The novel message is that privatisation exacerbates the problem of motivating the public to impose accountability on the government. This new result is intuitive. A only gains from pressuring its agent, $\mathrm{G}$, if $\mathrm{G}$ can respond efficiently. Under public provision, $\mathrm{G}$ responds by adapting at cost. Under private provision, the response is less attractive to A, since M extracts a share of G's adaptation surplus in the form of an inflated adaptation price.

\subsection{Strategic complementarity and substitutability in accountability}

Investments $i$ and $j$ are often strategic complements: the greater is G's attentiveness, the more sense it makes for A to investigate and communicate public preferences and to apply pressure on G; conversely, the more active is $\mathrm{A}$, the more $\mathrm{G}$ can gain from being attentive to $\mathrm{A}$ and to service issues. ${ }^{11}$ In this subsection, I show how strategic complementarity between $i$ and $j$ exacerbates the problem of privatisation, by analysing the mutual reinforcing knock-on effects of privatisation's direct effects on $i$ and $j$. Even though $i$ and $j$ are chosen simultaneously, my assumptions ensure that equilibria are unique, and it is straightforward to prove that the effects identified in propositions 1 and 2 continue to hold, with an increase in the advantages from public provision. When $i$ and $j$ are substitutes, the overall accountability effect is as before, but one of $i$ and $j$ could move in the opposite direction.

Proposition 3 If public pressure and government attentives are strategic complements - i.e.

$$
v_{i, j}(i, j)>0-\text { then: (i) } e^{\text {public }}<e^{\text {private }}(\alpha), j^{\text {public }}>j^{\text {private }}(\alpha), \forall \alpha>0, \frac{d e^{\text {private }}(\alpha)}{d \alpha}>
$$

\footnotetext{
${ }^{11}$ There are two reasons why $v_{i, j}>0$ might hold. First, communication is a two-sided activity: G must exert effort to listen to the demands of A (e.g. by inviting public participation and conducting surveys) or at least to monitor their political significance (in the case of public pressure on a reluctant government). So some degree of complementarity is always present and it is common to assume complementarity over the full range of relevant efforts (see e.g. Dewatripont and Tirole, 2005). Second, G's awareness of public preferences and public pressure only leads to adaptations if $\mathrm{G}$ knows how to satisfy these demands, so G's efforts in monitoring service provision and alternative provision options complement A's efforts to communicate and apply pressure.
} 


$$
\begin{aligned}
& 0, \frac{d j^{\text {private }}(\alpha)}{d \alpha}<0 ;(\text { ii }) v_{i j} \text { raises } i^{\text {public }}-i^{\text {private }}(\alpha) \text { and } j^{\text {public }}-j^{\text {private }}(\alpha) \text { but has no } \\
& \text { effect on } e^{\text {private }}(\alpha)-e^{\text {public }} . \text { If } i \text { and } j \text { are strategic substitutes, } v\left(i^{\text {public }}, j^{\text {public }}\right)> \\
& v\left(i^{\text {private }}, j^{\text {private }}\right) .
\end{aligned}
$$

Because of these complementarities, the timing of play is important. A sequential set-up in which the public move first (and the government observe this before moving) is plausible if one interprets the government's main receptiveness choice as one over effort to work out how to satisfy the mobilised public's demands. Having the public move second is relevant if, e.g., the government organises public meetings about service preferences and the public respond by supplying effort to actively participate in these meetings. The simultaneous setup that I treat here is relevant if the public cannot observe government efforts and the government must exert effort to discover the effectiveness of a mobilisation. The sequential time orderings reduce the likelihood of multiple equilibria and shift the effort levels, but do not interfere with the qualitative nature of my results.

\section{The privatisation decision}

In this section, I analyse the choice between the private and public provision alternatives, given the accountability and cost implications derived above. I study two cases. In the first, the government decides the provision mode. In the second, voters decide; for instance, the privatisation/municipalisation choice could be put to a referendum (voter preferences are also influential when political parties can make electoral commitments over their plans to privatise or nationalise/municipalise). Costs of switching between private and public modes of provision (say from expertise and organisational capital that build up in support of the current provision mode) may generate a strong status quo bias not captured here. However, these costs make it all the more important to be able to predict the long-run comparative levels of social welfare under the alternative provision modes. This section helps to answer this question, because the endogenous level of accountability for adaptations is a key component of long-run service quality.

If both the markets for employee managers and service contractors are perfectly competitive at stage 0 , the negotiation over $t_{0}$ (M's salary if a public employee and contract price if private) ensures that M's average equilibrium payoff equals M's market opportunity cost which I denote by $r$. So the respective values of $t_{0}$ in the public and private cases are determined by equating

the expressions for $u_{M}^{\text {public }}$ and $u_{M}^{\text {private }}$ from equations 2 and 6 with $r$. Substituting for $t_{0}$ into equations 1 and 5, respectively, reveals that G's payoff is given by the bilateral surplus with 
$\mathrm{M}$ evaluated at the subgame-perfect levels of $(e, i, j)$ :

$$
\begin{aligned}
u_{G}^{\text {private }, \alpha} & =b+v(i, j)-l(r+e-w(e))-i \text { at }(e, i, j) \text { satisfying equation } 8 \\
u_{G}^{\text {public }} & =b+v(i, j)-l(r+e-w(e))-i \text { at }(e, i, j) \text { satisfying equation } 4
\end{aligned}
$$

Whenever $\mathrm{G}$ chooses the private mode of governance, $\mathrm{G}$ chooses the contract length $\alpha$ that

maximises $u_{G}^{\text {private } \alpha}$. As explained in subsection 2.3, I have set up the model so that public provision is represented by the corner solution in which it is optimal for $\mathrm{G}$ to set $\alpha=0$. This permits almost direct application of the results from proposition 4a of Ellman (2006): increasing $l$ is equivalent to raising the "importance" of self-investment $e$, so from G and M's perspective, the optimal contract length increases with $l$. In particular, there exists $\hat{l}$ such that it is optimal to set $\alpha=0$, i.e. to adopt the public provision mode, for all $l>\hat{l}$. (Since this cutoff is determined by G's preference, I write $\hat{l}^{G}$.) To simplify, I assume $w^{\prime \prime \prime}(e) w^{\prime}(e)<4\left(w^{\prime \prime}(e)\right)^{2}$ and the same for $v$ with respect to $i$ and $j$ - these are sufficient conditions for all the problems of ( $\mathrm{G}$ and $\mathrm{A}$ and the public) optimising over $\alpha$ to be regular.

Proposition 4 If the government places sufficient weight on the quality of the public service relative to the cost of public funds, the government prefers public to private provision:

$$
\exists \hat{l}^{G}: l \leq \hat{l}^{G} \Rightarrow u_{G}^{\text {public }} \geq \sup _{\alpha} u_{G}^{\text {private }, \alpha}
$$

This result is intuitive. From G and M's perspective, $i$ and $e$ should be such that $w^{\prime}(e)=1$ and $v_{i}(i, j)=1$ and the higher is $j$, the better. So they are concerned about underinvestment in $e, i$ and $j$. Privatisation raises $e$ towards the optimum level, but exacerbates the underinvestment in $i$ and $j$ since it reduces G's ability to appropriate the returns from improving service quality.

\section{$5 \quad$ Public pressure and accountability}

In the introduction, I presented my two leading interpretations of the accountability mechanism. In the first interpretation, accountability is enhanced by discovery and communication of adaptation alternatives. In the second interpretation, accountability increases with public pressure. In this section, I formalise the second approach. I first show how the pressure interpretation can be consistent with my payoff assumptions. I then explain how public pressure may decrease G's payoff and I derive the implications.

When $i$ and $j$ represent public pressure, the degree to which $\mathrm{G}$ internalises public welfare becomes endogenous. The relationship between $\mathrm{G}$ and A's payoffs is more complex. For instance, pressure that affects G's value of an adaptation, need not have any effect on the public's 
value of that adaptation. Nonetheless, pressure that raises the likelihood that the adaptation will be implemented by $\mathrm{G}$ and $\mathrm{M}$ in equilibrium. It is as if adaptations that are not sufficiently politically salient to be attractive to $G$ had not been discovered. So publicity investments have a similar effect to participatory investments that help discover useful adaptations. I formalise with a simple model in which $\mathrm{G}$ and A's equilibrium investment returns are again proportional.

A single possible service adjustment, such as fixing a problem in the public service, becomes apparent over time. Pressure $j$ raises the probability $q(j)$ that the service adaptation is as politically salient as the basic service value and the public cost of funds. For instance, the majority of the public might observe the adaptation decision before voting with probability $q(j)$ and otherwise not observe it at all. The basic service and public expenditure (surplus/deficit) are always politically salient, so $G$ never implements non-salient adaptations. G therefore implements the adaptation with probability $q(j)$. G's electoral concerns lead $\mathrm{G}$ to internalise the fraction $g$ of the public value from the basic service and to internalise, when politically salient, the same fraction of the public value $S$ from adaptation. So G's expected gain from making adaptations at cost is $g S q(j)$. A's gain from implementation of the adaptation is $a S-$ independently of whether $j$ succeeds in creating political salience - but since adaptations are only implemented when salience is high, A's expected gain is $a S q(j)$. In this special case, G and A's expected payoffs remain exactly proportional in the ratio $\frac{g}{a} \cdot{ }^{12}$ So the above results continue to hold.

However, public pressure usually has an additional effect: it hurts bad or unlucky politicians (as well as helping good or lucky politicians and increasing incentives). The simplest motivation for this claim is that an uninformed public cannot distinguish and therefore vote against bad politicians, so a public pressure campaign that informs the public lowers a bad politician's chances of success. If bad politicians are those that fail to make valuable adaptations, public pressure $j$ reduces G's payoff in the contingency where $\mathrm{G}$ fails to make the adaptation. I could therefore assume that when the service issue is politically salient, $G$ suffers a loss $-\theta$ if $G$ fails to implement the adaptation; fixing G's payoff from implementing the adaptation, G's payoff accordingly falls by $\theta q(j)$. An alternative perspective, with the same implications, posits that the public always gains some payoff $\theta$ from the service, where $\theta$ is high if the service situation is favourable, but is only aware when the service issue is salient, so G only internalises $g \theta$ with probability $q(j)$.

$\mathrm{G}$ and A's returns on $j$ are no longer exactly proportional, but the holdup results are

\footnotetext{
${ }^{12}$ This example is readily extended. E.g. if $\mathrm{G}$ is only sufficiently aware of public pressure and how to respond with probability $q(i)$, then the probability of an adaption in equilibrium is $q(i) q(j)$. Again G and A's expected gains remain proportional.
} 
unchanged - they only depend on G and A's benefits from equilibrium adaptations and the losses from public transfers to M. What changers are G's preferences for privatisation relative to the public's preferences. It is immediate that $\mathrm{G}$ has a stronger preference/willingness to accept $j$, the greater is $\theta$. Since $j$ is higher under public provision, $\mathrm{G}$ is more likely to prefer public provision, the greater is $\theta$. Meanwhile, $\theta$ has no effect on A's and the public's preferences over provision mode.

Proposition 5 In the pressure model, $j$ varies with the private/public choice of mode exactly as before; so $G$ 's preference for privatising is increasing in $\theta$.

This proposition reflects how G may use privatisation as a way to escape accountability pressures. I verify that the public's privatisation preference is independent of $\theta$, by noting that the utilitarian measure of social welfare is,

$$
\frac{1}{g}(b+q(j) v(i)+\theta-l(r+e-w(e)))+r-i-j
$$

It follows immediately that,

Proposition 6 From the public's perspective, a high value of $\theta$ biases $G$ towards public provision and a low value of $\theta$ - say, bad news about the public service which could potentially be blamed on $G$ - bias $G$ towards privatising.

\section{Discussion}

Undesirable accountability. Pragmatists may point out that all my arguments are invalid or inverted in situations where public pressure is infeasible or undesirable. ${ }^{13}$ Acknowledging these problems helps to refine the theory's empirical predictions and policy recommendations. First, in settings where public pressure possibilities are remote, the accountability benefits of public provision may be small and with partial market pricing to buttress private provision, privatisation may be preferred by many. Consistent with this, Jacobson and Tarr (1995) point out that in the U.S., water supply tends to be privatised when the recipient public are subdivided by political boundaries. However, since democratic accountability builds up over time, public provision's tendency to induce public activism may have vital long-run benefits in settings where democratic pressure is initially limited.

\footnotetext{
${ }^{13}$ In my theory, public provision maximises dynamic accountability, because the government can always force a public provider to adapt to changing demand: the government can replace or at least sideline an incumbent public manager who disobeys orders to adapt the service. Public management is much less effective when rigidly bureaucratic, but my theory suggests increasing bureaucratic accountability instead of privatising.
} 
Second, accountability can reduce welfare if the public are sufficiently myopic or manipulated by strong interest groups. For instance, economists have long argued that central bankers should be immunised against myopic electoral pressures and more recently, Maskin and Tirole (2004) analysed the problem of "pandering" when public servants are elected ("politicians") rather than appointed (like a judge). (They study information problems rather than moral hazard. ${ }^{14}$ ) Bennedsen's (2000) lobbying model and Milrom and Roberts' (1988) influence cost model point to related concerns. In my initial model, there is no risk of A taking excessive efforts, because A's goals are fully aligned with other members of the public. However, when $A$ is replaced by a special interest lobby, $G$ might divert attention onto selected public services that benefit those interests. This creates a risk that $G$ and A's efforts reduce social welfare. Privatisation might then be advantageous by reducing the risk of over-politicising the public service. $^{15}$

Bureaucracy. It is possible for accountability to be lower under public provision if the mayor has difficulty monitoring and controlling public servants who are self-interested. However, these accountability problems if bureaucrats can be forced to be more responsive to politicians (what Adams and Hess (2000) call "de-Sir-Humphreying" the civil service). Furthermore, it is sometimes possible to make the heads of service providing agencies directly accountable to the public by having the public elect these heads. This step towards direct democracy has been studied by Besley and Coate (2003) among others as I discuss next.

Direct democracy. My analysis suggests unusual questions, such as what would happen if the public could vote directly to select a firm to provide services under a long-term contract, and perhaps also vote directly to oust the firm if activists manage to collect enough signatures of discontent? Given that the public benefits are dispersed across many people, monitoring possible providers and writing effective contracts tends to require specialised agents, such as the mayor or a service agency head. Nonetheless, asking this question can illuminate design issues. The mayor is only useful if effectively monitored by the public, but why is it easier to monitor the mayor than the service provider?

\footnotetext{
${ }^{14}$ The "public choice" school argues that public management leads to a bureaucratic interest group that interferes with accountability, but privatised provision also generates interest groups. Accountability is harmful when politicised actors pander to a myopic public (see Maskin and Tirole (2005)), but unlike central banking, the fundamental problem in public service provision is contract incompleteness, not time inconsistency. Democratic accountability is needed, because services must be adapted to unanticipated changes in public demand.

${ }^{15}$ When $i$ and $j$ reduce the salience of other political decisions, there is a risk of creating an imbalance in accountability. On the other hand, enhancing $e$ may not always be advantageous either. Privatisation could then be damaging by over-motivating $e$. For instance, if M's investments in cost-cutting reduce G's payoff from the basic service contract, there is a risk that long-term contracting leads to excessive investment by $\mathrm{M}$ - see HSV or Ellman (2006) who categorises this as a negative cross effect.
} 
Information access. The cost of getting information or verifiable evidence about service quality can be a major barrier to activist pressure. Since public organisations are often governed by laws that guarantee greater public access to information, privatisation may decrease accountability by simply restricting access to information. From a theoretical perspective, it is not obvious why transparency cannot be imposed as a condition for eligibility of private providers in public service contract competitions. One possibility is that the appropriate governance structure will take time to create. Certainly, private service providers work hard to argue that their legal obligations to their shareholders and their competitive pressures require that they maintain most of the standard privacy rights of private firms. Another possibility is that information disclosure cannot be forced by contract. The mayor needs to monitor and pressure for transparency. If, as argued above, private provision shifts most responsibilities onto the provider, then the mayor may more often manage to excuse herself for not forcing information disclosure, say by pleading ignorance.

Endogenising the government's preference function. In a companion paper, I analyse voting explicitly. Voters study the incumbent mayor's performance in order to predict their expected payoffs from reelecting this mayor. This permits foundations for the assumptions about the government's payoff function used in this paper. There, I consider two possibilities. One is to assume that voters are retrospective as in Ferejohn (1974). The other is to allow for forward-looking voters in a rational choice setting where G's only goal is to take ego rents $R$ from holding office. This approach allows me to analyse a "responsibility shifting" effect of privatisation.

Contract length, design and inherited holdups. Ellman (2006) identifies a tradeoff between lengthening performance contracts to better motivate cost-cutting investments by the provider and shortening the contracts to reduce holdup of adaptation investments. Here, I extend this result by analysing the possibility that an incumbent government is replaced by an opposition party, before the incumbent's performance contract with a private provider has come to an end.

Analysis of the electoral competition reveals a particularly worrying effect of contracts that span across elections. Accountability is much enhanced when opposition parties can make specific policy commitments - see Austen-Smith and Banks (1989 and 2005). For instance, the public are more likely to oust an incumbent mayor for failing to fix a service problem (such as water quality falling below a recognised standard) when the opposition mayor has credibly committed to fix the problem. Unfortunately, if the service is managed by a private provider under a performance contract that spans the electoral cycle, this mayor suffers from a particularly pernicious holdup problem: if she wins after committing to solve the service 
problem, the service provider can hold her up over the entire value of her reputation for keeping promises. If voters anticipate the tax implications of this "inherited holdup", such commitments are less attractive to voters as well as opposition parties. Privatisation therefore reduces the likelihood that opposition mayors make firm policy commitments to improve service quality. This concern is particularly significant in Public-Private Partnerships (PPPs) where the private service provider is also responsible for building the facilities to be used (see Hart (2003)), because the private party usually then needs a contract in excess of five years to properly exploit its non-contractible sunk cost investments. So, for settings where effective privatisation requires contracts that exceed the four or five year term limit on governments, my analysis suggests that privatisation is particularly damaging - at least if political accountability is important.

\section{Conclusion}

Critics have claimed that under privatisation, the government will wash its hands of service problems and quality will decline. This paper demonstrates a rigorous foundation for a less extreme version of this concern. The blunt version of this pessimistic view - maintaining that people will not hold the government responsible for policy outcomes because privatisation places control in the hands of a private company - is incomplete. The government's role (as holder of the purse-strings) remains critical under privatisation. In particular, the government can choose to which private company to delegate (just as it may control which civil servant is in charge of the relevant public agency under public provision) and even during a given provider's contractual term, the government can at least negotiate (offering to pay additional costs if need be). ${ }^{16}$ A more refined version of the argument therefore had to explain why, under privatisation, the government might be held less responsible and/or why pressuring the government should be less effective.

Privatisation of public services transfers control rights and contractual obligations to providers. I showed that, while improving cost reduction incentives, privatisation may decrease accountability and responsiveness of government to public concerns about service quality. I endogenised public mobilisations that can make government accountable for service quality. Political accountability induces the incumbent government to adapt services to meet public demand, but under privatisation, the provider can hold up the government by charging an inflated price for service adaptation. This holdup has an externality on the public, because the government

\footnotetext{
${ }^{16}$ The government can also regulate, but regulation is necessarily limited: in the extreme case of unlimited regulation, the government retains full residual control rights; this is effectively public provision.
} 
pays using public funds. The holdup therefore reduces the public's incentive to mobilise to apply pressure on the government. The holdup also directly demotivates the government from exerting effort to evaluate public demands and their electoral implications. Finally, public mobilisation and government receptiveness are often complementary, making the two effects mutually reinforcing.

My theory can explain the evidence that privatisation sometimes lowers service quality, and the mechanism is very different to alternative explanations, which identify a "negative externality of incentives" (on non-contractible quality) - for instance, HSV argue that privatisation reduces service quality by raising incentives to reduce cost. Those explanations cannot explain why consumers might, as in Kwoka's (2000) dataset, benefit from lower unit prices when a service is publicly managed. By contrast, my accountability mechanism can explain this: privatisation dissuades the public from mobilising to pressure the government to restrain consumer prices.

My analysis has a number of policy implications. In particular, if privatisation is pursued, then the creation of credible cost-measurement agencies (to allow cost-plus contracting), the adoption of dual suppliers, the subsidisation of incumbent challengers and the use of shorter contracts (at least not spanning elections which create an inherited holdup problem) offer partial but imperfect ways to reduce the accountability problem; the formation of relational contracts could also help, but is at odds with the anti-corruption strategy of requiring selection of the lowest bidder. Interestingly, recent suggestions to require private providers to exceed a minimal satisfaction rating in consumer surveys effectively represent a small step towards direct democracy where people's votes select the service provider. Further work could investigate the use of not-for-profit restrictions and direct election of the public servants controlling service provision.

In sum, the main contributions of this paper are to identify settings in which privatisation is particularly damaging to political accountability and to indicate how privatisation could be designed to limit the interference with accountability.

\section{References}

Adams, D. and M. Hess, "Alternatives to Competitive Tendering and Privatisation: A Case Study from the Australian Health Industry," Australian Journal of Public Administration, 59(1), 2000, 49-59.

Austen-Smith, D. and J. Banks, "Electoral Accountability and Incumbency in Models of Strategic Choice in Politics," P. Ordeshook (ed.) Ann Harbor: University of Michigan Press 
(1989).

Bennedsen, M., "Political Ownership," Journal of Public Economics, 2000.

Besley, T., and R. Burgess, "Information and State: Political agency, government responsiveness and the role of the media," European Economic Review 45 (2001) 629-640.

Besley, T., and R. Burgess, "The Political Economy of Government Responsiveness: Theory and Evidence from India," Quarterly Journal of Economics, Volume 117, Number 4, November (2002) pp. 1415-1451(37).

Besley, T., and S. Coate, "Elected versus Appointed Regulators: Theory and Evidence," Journal of the European Economic Association, 2003.

Ellman, M., "A Theory of the Optimal Duration of Contracts with Application to Outsourcing," (2006) UPF mimeo.

GCBA (Gobierno de la Ciudad Autónoma de Buenos Aires Government of the Autonomous City of Buenos Aires), Presupuesto Participativo: Una Realidad, Buenos Aires, 2003.

Guasch, (2005)

Hart, O., "Incomplete Contracts and Public Ownership: Remarks, and an Application to Public-Private Partnerships," Economic Journal (2003) 113, 69-76.

Hart, O, Shleifer, A.S., and R.W. Vishny "The Proper Scope of Government: Theory and Application to Prisons," QuarterlyJournal of Economics (1997) 112, 1127-1161.

Heller, P., "Moving the State: The Politics of Democratic Decentralization in Kerala, South Africa and Porto Alegre," Politics and Society, 29:1 (2001), pp.131-163.

Jacobson, C., and J. Tarr, "Ownership and Financing of Infrastructure," World Bank Policy Research, Working Paper 1466, June (1995).

Kessler, A. and C. Lülfesmann, "Monitoring and Productive Efficiency in Public and Private Firms," Finanzarchiv (2002), February, Vol. 58(2), pp.167-187.

Kwoka, J., "Governance Alternatives and Pricing in the U.S. Electric Power Industry," Journal of Law, Economics, \& Organization, April (2002).

Kwoka, J., "The Comparative Advantage of Public Ownership: Evidence from U.S. Electric Utilities," Canadian Journal of Economics, May (2005) 38(2).

Laffont, J-J., and J. Tirole, "Privatization and Incentives," Journal of Law, Economics and Organization (1991) 7, 84-105.

Lawrence, F., and K. Quarmby, "Private deals block Jamie's school dinners," The Guardian, April 25, 2005.

Maskin, E., and J. Tirole, "The Politician and the Judge, Accountability in Government," American Economic Review (2004) 1034-1054.

Pollock, A., J. Shaoul, D. Rowland and S. Player, "Public services and the private sector: A 
response to the IPPR," November 2001, revised with a new foreword by David Hinchliffe MP (Chair of the House of Commons Health Select Committee).

Schmidt, K., "The Costs and Benefits of Privatisation: An Incomplete Contract Approach," Journal of Law, Economics and Organization (1996) 12 1-24.

Shapiro, C. and R. Willig, "Economic Rationales for the Scope of Privatization," in E. N. Suleiman and J. Waterbury (eds.), The Political Economy of Public Sector Reform and Privatization. Boulder,Colorado: Westview Press.

Shleifer, A., "State versus Private Ownership," Journal of Economic Perspectives (1998), 12, 113-50.

\section{$9 \quad$ Appendix}

\section{Proof of proposition 3}

The first-order condition for $e$ is unchanged so proposition 1 gives the result for $e$. The firstorder conditions for $i$ and $j$ can be written as $D v(i(\alpha), j(\alpha))=\frac{2}{2-\alpha k}\left(\begin{array}{c}1 \\ \frac{g}{a}\end{array}\right)$. Differentiating this identity with respect to $\alpha$,

$$
\begin{aligned}
D^{2} v(i(\alpha), j(\alpha))\left(\begin{array}{c}
\frac{d i}{d \alpha} \\
\frac{d j}{d \alpha}
\end{array}\right) & =\frac{2 k}{(2-\alpha k)^{2}}\left(\begin{array}{c}
1 \\
\frac{g}{a}
\end{array}\right) \text { so } \\
\left(\begin{array}{c}
\frac{d i}{d \alpha} \\
\frac{d j}{d \alpha}
\end{array}\right) & =\frac{2 k}{(2-\alpha k)^{2}} \frac{1}{\Delta}\left(\begin{array}{cc}
v_{j j}(i(\alpha), j(\alpha)) & -v_{i j}(i(\alpha), j(\alpha)) \\
-v_{i j}(i(\alpha), j(\alpha)) & v_{i i}(i(\alpha), j(\alpha))
\end{array}\right)\left(\begin{array}{c}
1 \\
\frac{g}{a}
\end{array}\right) \\
& =\frac{2 k}{(2-\alpha k)^{2} \Delta}\left(\begin{array}{c}
v_{j j}(i(\alpha), j(\alpha))-\frac{g}{a} v_{i j}(i(\alpha), j(\alpha)) \\
\frac{g}{a} v_{i i}(i(\alpha), j(\alpha))-v_{i j}(i(\alpha), j(\alpha))
\end{array}\right)
\end{aligned}
$$

where $\Delta=v_{i i}(i(\alpha), j(\alpha)) v_{j j}(i(\alpha), j(\alpha))-\left(v_{i j}(i(\alpha), j(\alpha))\right)^{2}>0$ by assumption 2 .

If $v_{i j}>0$, then $i$ and $j$ both decrease with $\alpha$ (since $v_{j j}, v_{i i}<0$ and $g, a>0$ ); furthermore, the rate of decrease is increasing in $v_{i j}$.

If $v_{i j}<0$, then either $i$ or $j$ still decreases (else $a\left|v_{j j}\right|<g\left|v_{i j}\right|$ and $g\left|v_{i i}\right|<a\left|v_{i j}\right|$ so $v_{i i} v_{j j}<v_{i j}^{2}$, contrary to assumption 2); furthermore, $\frac{d}{d \alpha} v(i(\alpha), j(\alpha))$

$$
\begin{aligned}
& =D v(i(\alpha), j(\alpha))^{\top}\left(\begin{array}{c}
\frac{d i}{d \alpha} \\
\frac{d j}{d \alpha}
\end{array}\right)=\frac{2}{2-\alpha k}\left(1, \frac{g}{a}\right)\left(\begin{array}{c}
\frac{d i}{d \alpha} \\
\frac{d j}{d \alpha}
\end{array}\right) \\
& =\frac{2}{2-\alpha k} \frac{2 k}{(2-\alpha k)^{2} \Delta}\left(v_{j j}(i(\alpha), j(\alpha))-\frac{g}{a} v_{i j}(i(\alpha), j(\alpha))+\frac{g}{a}\left(\frac{g}{a} v_{i i}(i(\alpha), j(\alpha))-v_{i j}(i(\alpha), j(\alpha))\right)\right) \\
& =\frac{4 k}{(2-\alpha k)^{3} \Delta}\left(v_{j j}(i(\alpha), j(\alpha))-2 \frac{g}{a} v_{i j}(i(\alpha), j(\alpha))+\left(\frac{g}{a}\right)^{2} v_{i i}(i(\alpha), j(\alpha))\right)
\end{aligned}
$$


which is always negative since even when $\frac{g}{a}$ takes the value, $\frac{v_{i j}}{v_{i i}}$, that maximises the term in parenthesis, this term is still negative (it equals $\frac{v_{j j} v_{i i}-v_{i j}^{2}}{v_{i i}}<0$ ). So the expected equilibrium value of adaptations falls with $\alpha$.

\section{Proof of proposition 4}

The proof is a direct application of proposition $4 \mathrm{~b}$ from Ellman (2006). There is one minor complication: since $j$ is chosen by a third party (A), G and M neglect the costs of $j$; this changes the form of the optimand, but the benefit through $j$ from increasing $\alpha\left(v_{j}(i, j) j^{\prime}(\alpha)>0\right)$ is independent of $l$, so the proposition remains valid. 